YONG CUI ${ }^{1,4}$

E-mail: yong.cui@ievvwi.uni-stuttgart.de

Traffic Policy

Review

STEFAN TRITSCHLER ${ }^{2}$

E-mail: stefan.tritschler@vwi-stuttgart.de

ULLRICH MARTIN ${ }^{1}$

Submitted: 10 Novr 2019

E-mail: ullrich.martin@ievvwi.uni-stuttgart.de

FAN $\mathrm{MO}^{3}$

(Corresponding author)

E-mail: mofan61@163.com

${ }^{1}$ Institut für Eisenbahn- und Verkehrswesen

der Universität Stuttgart

Pfaffenwaldring 7, 70569 Stuttgart, Germany

2 Verkehrswissenschaftliche Institut Stuttgart GmbH

Torstaße 20, 70173 Stuttgart, Germany

3 Tongji University

1239 Siping Rd, Yangpu Qu, Shanghai Shi

200000, China

${ }^{4}$ Hefei University

373 Huangshan Rd, Shushan Qu, Hefei Shi, Anhui Sheng,

23003, China

\title{
STANDARDISED EVALUATION OF SHANGHAI-HANGZHOU HIGH-SPEED MAGLEV PROJECT
}

\begin{abstract}
In recent years, high-speed maglev systems have received renewed attention once again. However, a systematic and transparent approach to evaluate high-speed maglev projects does not currently exist, which could be an obstacle for their application, even with technical success. In Germany, the Standardised Evaluation is applied as a basis for decision making regarding the public funding of projects. It should be implemented for all investments of urban public transport projects with a value of more than $€ 25$ million. In this paper, the economic evaluation for the Shanghai-Hangzhou maglev project is carried out with the Standardised Evaluation. One of the most important contributions of this work is to demonstrate the applicability of Standardised Evaluation for high-speed maglev projects. With the Standardised Evaluation, the evidence of macroand microeconomic benefit can be presented in a transparent and systematic way. The result can be used to prove the project's profitability and to rank different projects or project alternatives.
\end{abstract}

\section{KEY WORDS}

Standardised Evaluation; high-speed; maglev; transport systems design;

\section{INTRODUCTION}

As a competitor of high-speed railway systems and airlines, the application of high-speed maglev systems (with the maximum speed of more than 250 $\mathrm{km} / \mathrm{h}$ ) has not been very straightforward. Currently, the only commercially operated high-speed maglev line in Shanghai consists of a total length of $30.5 \mathrm{~km}$. Many proposals, for example, the Shanghai-Hangzhou maglev line, the Munich airport Transrapid line, and the London-Glasgow line, have been cancelled and rejected for various reasons. The greatest obstacle in the way of implementing high-speed maglev systems is the uncertainty of the economic benefits and costs involved with their implementation. Both from the macroeconomic and microeconomic points of view, the profitability of high-speed maglev projects remain a point of controversy.

In China the recent years have seen the development of certain new applications on middle and lowspeed maglev lines (with a maximum speed up to 120 $\mathrm{km} / \mathrm{h}$ ), while high-speed maglev projects have again been proposed. In 2011, permission was granted for the construction of the Chuo Shinkansen project in Japan. China, meanwhile, started a research and development maglev project with maximum operation speed of $600 \mathrm{~km} / \mathrm{h}$ in 2016 . High-speed maglev systems are expected to achieve a higher speed in operations than the traditional high-speed railway systems.

However, a systematic and transparent approach to evaluate high-speed maglev projects does not exist as of yet, which could be an obstacle for the application of even technically-sound proposals. Therefore, a cooperation project was carried out between Universität Stuttgart, VWI Stuttgart GmbH, and Tongji University in 2016 with the goal of assessing the applicability of using German Standardised Evaluation for high-speed maglev projects, and of investigating the requirements 
to transfer the evaluation method in China. The Shanghai-Hangzhou maglev line is used for the case study. During the timespan of the project, the version 2016 of the Standardised Evaluation [1] was not published. The research was, therefore, carried out based on version 2006 [2]. The applied "with case" and "without case" principle (see Section 3) and the annuity method (see Section 3.1) of the two versions are the same. In version 2016, a new component "benefit of creating additional mobility opportunities" is included in an optional model building block. The method to evaluate the indicator on the balance of noise emission is revised. The cost factors and the parameters are updated according to the current price index in 2016 version. The verbal description and the evaluation indicator E2 (see Section 3.1) are not included in the new version. A new design of the template forms is applied to adapt a more flexible form to IT solution. Since these adjusted factors should be also further modified according to the current and the forecast value in China, the difference of the evaluation results with these two versions should not be significant.

In this paper, the existing evaluation method and the challenges in the evaluation of maglev projects will be described in Section 2. The introduction of the German Standardised Evaluation is given in Section 3. A detailed evaluation on the investigated project is presented in Section 4. Finally, the results and further suggestions regarding the use of the evaluation method are discussed in Sections 5 and 6.

\section{EXISTING METHODS AND CHALLENGES}

In recent decades, several works of research have been carried out on the evaluation of high-speed maglev projects. The benefits relating to environment, energy and economics for high-speed maglev systems and high-speed railway systems are compared in [3]. Their operating characteristics and engineering aspects are evaluated in [4] with the case study of the Beijing-Shanghai line. The investigation in [5] addresses advantages possessed by high speed rail systems over maglev systems, due to the small differences between the travel time, the high compatibility of high-speed railway, and the uncertain investment and operating costs of maglev systems. On the contrary, the superiority in travelling time, economic efficiency and environmental behaviour of high-speed maglev systems is outlined by [6]. The environmental impacts have also been deeply investigated. The $\mathrm{CO}_{2}$ emissions of maglev train systems is analysed for its full lifecycle in [7]. An evaluation of the environmental impacts for the Shanghai-Hangzhou maglev project (see Section 4.1) was published in [8], in order to address the feedback and suggestions from the community regarding its environmental impacts and possible protection. The above-mentioned research accumulated plenty of experiences on the evaluation of high-speed maglev projects. However, most of the evaluations only focus on certain isolated aspects, and a comprehensive overview and comparison between the different systems are absent.

A multi-criteria approach is also used in some works. In [9], weights are assigned to particular criteria with an entropy method in order to compare high-speed rail, transrapid maglev and air passenger transport in Europe. In [10], the limits of traditional evaluation methods are outlined. The high-speed maglev systems and German high-speed railway ICE systems are compared, with a multidimensional and multi-criteria approach. However, this approach is not able to create an explicit decision for decision makers. A review of using multi-criteria methods is given in [11], in which the difficulties of the multi-criteria approach are emphasized. The evaluation criteria may be measured in different dimensions, and it is a challenge to transform and integrate the criteria into one unified dimension. There may be a rift between the preferences of stakeholders and the produced results if the decision makers and the involved stakeholders do not understand or agree with the entire methodological approach.

As high-speed maglev is a new type of public transport system, the parameters of the existing evaluation methods are not specifically tailored to it [10]. As such, the uncertainty of its evaluation is comparatively higher than that of other traditional transport systems.

In summary, some of the existing evaluation methods for maglev projects do not cover all the relevant aspects sufficiently. Other methods are limited due to their lack of transparency and comprehensibility. In this paper, an evaluation method using German Standardised Evaluation ([2, 12]) is applied. After the introduction of Standardised Evaluation, the reasons for applying this approach will be explained in Section 3.2.

\section{INTRODUCTION OF STANDARDISED EVALUATION}

The method "Standardised Evaluation of Infrastructure Investments for Urban Public Transport" (hereby referred to as "Standardised Evaluation" in this paper) was developed in 1980s [13]. Currently, this method is the basis for decision making regarding the public funding of projects according to the German municipal traffic financing law (Gemeindeverkehrsfinanzierungsgesetz - GVFG). The Standardised Evaluation is to be implemented for all investment projects with a value of more than $€ 25$ million. The main fields of application for this evaluation method are for the new construction of tracks for trams, subways, and suburban/ regional trains. 
The goal of the Standardised Evaluation is the transparent disclosure of any impacts the public transportation investment project may have in order to properly assess any possible project-related conflicts. The Standardised Evaluation also:

- provides evidence of the macroeconomic benefits of the project and therefore, justification for it to be funded through public funding bodies.

- demonstrates its financial impacts in the form of microeconomic follow-up costs to the governmental awarding authorities who are financially responsible for the project in the case of a deficit, and the transportation company requesting the project to be built.

- shows whether the project complies with the principles of efficiency and cost-effectiveness when using public funds.

The macroeconomic impact is adequately determined, if different individual project alternatives can be compared. Therefore, the Standardised Evaluation (as well as other evaluation methods) use the "with case" and "without case" principle:

- Without case: The case (in the future) without the investment project

- With case: The case (in the future) with the investment project

When comparing the "with case" and "without case", other existing and planned public as well as individual transport systems are investigated as well. Hence, the evaluation will be carried out with additional consideration given to the future development of other possible alternatives.

\subsection{Evaluation indicators and the annuity method}

In the Standardised Evaluation, the balance of sub-indicators should be calculated in order to compare the difference between the "with case" and the "without case". In Section 5.1, the calculation of the balance of the sub-indicators will be described in detail. At the end of the evaluation, the calculated sub-indicators are combined to form the evaluation indicators. Two different types of evaluation indicators are contained within the Standardised Evaluation (version 2006), which differ in the evaluation of benefits either on a monetary scale or in the form of a point scale:

- The evaluation indicator E1 only includes costs and benefits in monetary form. These costs and benefits are either originally in monetary form (e.g. personnel costs) or were monetized (e.g. gains in travel time). E1 is calculated by comparing the benefits (which can also be negative) with the costs (in the form of the debt service for the project).

- The evaluation indicator E2 compares the benefits (which can also be negative) in the form of a point scale with the costs in monetary form (in the form of the debt service for the project).
In addition to the two evaluation indicators, E1 and E2, further effects of the proposed project can be described on a purely verbal basis. However, the evaluation indicator E2 and the verbal description are not directly used to assess the macroeconomic benefits and the eligibility of infrastructure projects and are, therefore, not considered in this work. Since the verbal description and the evaluation indicator E2 are rarely used in practice, they are no longer included in version 2016 of the Standardised Evaluation.

Cost Benefit Analysis (CBA) is applied for the evaluation indicator E1. In CBA, the comparison of costs and benefits are evaluated monetarily. Only the monetary aspects of the investment project or the aspects that can be monetized are considered. Some originally non-monetary terms, for example, the benefits of saved travel time, are converted in monetary terms by using pre-defined price indexes. The CBA is the economic version of the classic investment calculation that aims to choose the project with the highest benefits by calculating the cost-benefit ratio and the net benefit from a set of different alternatives. Projects with a higher cost-benefit ratio are preferable to those with a lower cost-benefit ratio. The cost-benefit ratio can therefore, also be useful when several projects are to be financed from the same limited budget.

In the Standardised Evaluation, all calculations are based on a yearly time interval. Due to this, the annuity method is used for the calculation of the infrastructure and vehicle (capital) costs. With this method, the net present values are distributed into average annual amounts. If it is found that the annual cash flows are of different values, the annuity factor (also known as the recovery factor) is used to convert them into steady and equal annual payments.

$A^{z}=C_{0}^{z} \cdot \frac{(1+d)^{T} \cdot d}{(1+d)^{T}-1}$

where:

$A^{z}$-annuity [CNY];

$d$-social discount rate;

$T$-time period (e.g. service life of individual components);

$C_{0}^{z}$-the total infrastructure investment [CNY].

In this paper, the unit of monetary evaluation is based on "Chinese yuan" (ab. CNY), since the original data were provided in Chinese currency. In the year 2018, one CNY can be converted into 0.13 EUR.

\subsection{Assessment of maglev project with Standardised Evaluation}

As discussed in Section 2, many existing methods cannot cover all relevant aspects sufficiently during their evaluation process. The Standardised Evaluation takes into full consideration all of the effects and impacts of public transportation projects. Both the 
macroeconomic benefits as well as the financial impacts are assessed. Therefore, the completeness and the integrity can be ensured through this approach.

In the Standardised Evaluation, a mature and systematic approach has been established to transform the evaluation criteria from different dimensions into one unified dimension. For example, not only the construction, operating and maintenance costs, but also the emissions of noise or $\mathrm{CO}_{2}$, time savings, and the impacts of accidents, can be measured as E1 in a monetary form. The traceability is provided from the results to the original units. In addition, other aspects including land use, riding comfort, as well as the indirect benefits for the economy and industrial development, are measured as E2 on a point scale. Therefore, as a comprehensive and understandable approach, the Standardised Evaluation is suitable for the evaluation of maglev projects.

In principle, the German Federal Transport Infrastructure Plan (BVWP, Bundesverkehrswegeplan) could also be applied, which is used to evaluate long distance public transport projects in Germany with similar approaches to the Standardised Evaluation. However, the Standardised Evaluation was originally developed for evaluating urban public transport projects. Since many maglev projects for urban public transport have been successfully implemented in recent years, the calibrated parameters gathered from these projects can be directly used in the Standardised Evaluation. At the moment, certain new high-speed maglev projects with relatively short distances are proposed for the purpose of demonstration and technical evaluation.
In these projects, the characteristics of urban public transport are the principle concern. For example, the effects of integration in urban public transport for the Shanghai-Hangzhou maglev project are investigated in this paper. Critically, maglev projects with a high operating speed will cover a large area of an urban region. The term "urban region" is then extended to describe the growing urban regions (for instance in China) with long travel distances. In addition, the new version of the Standardised Evaluation is also adjusted according to the current version of BVWP. Therefore, among others, the Standardised Evaluation is adopted to evaluate high-speed maglev projects, rather than the Federal Transport Infrastructure Plan.

\section{APPLYING STANDARDISED EVALUATION}

\subsection{The Shanghai-Hangzhou high-speed maglev project}

The feasibility study of the Shanghai-Hangzhou high-speed maglev project was initiated in 2006 [14]. In Figure 1, the proposed high-speed maglev line is illustrated. The blue line denotes the existing maglev line between Pudong-Airport and Longyang-Metro station. A green airport line was planned to connect Pudong-Airport and Hongqiao-Airport, which serves as an integrated transportation hub with connections for different means of transport, including aviation, railway, bus, metro and taxi. The red line should connect the two cities, Shanghai and Hangzhou. The region along this line has the highest population density and the

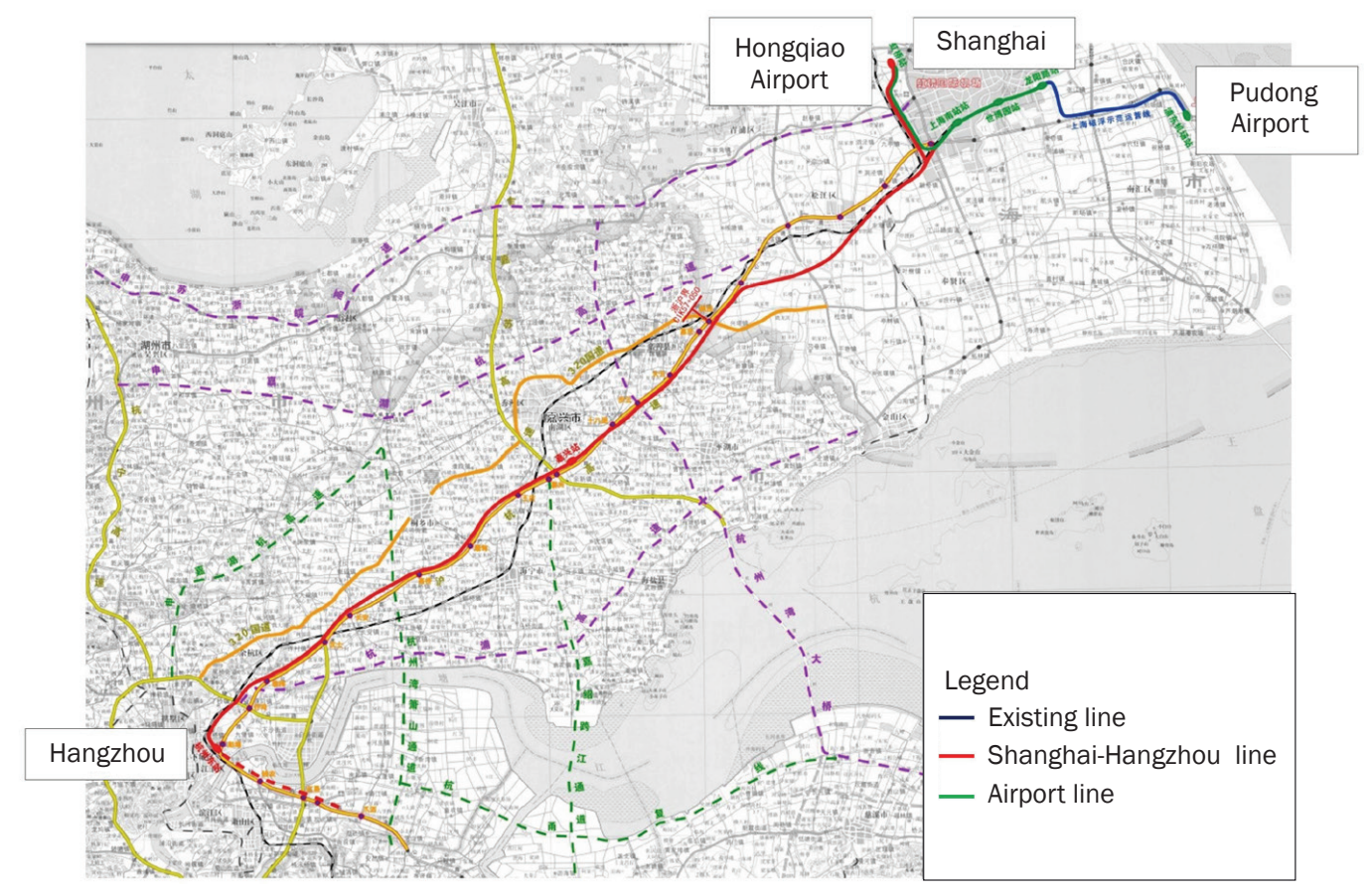

Figure 1 - The Layout of Shanghai-Hanzhou high-speed maglev line Source: SMTC et al. 2007 
highest level of economic and urban development in China. The capacity of the existing infrastructure was not able to meet the increasing traffic demand at that time. In the feasibility study, the total length of the new line is 199,434 km, including a 34,857 km airport line (the green line) and a $164,577 \mathrm{~km}$ Shanghai-Hangzhou line (the red line).

Several benefits were expected with the implementation of this project. The planned Shanghai-Hangzhou maglev line could provide high-speed passenger transport between the two cities within 30 minutes with the design speed of $450 \mathrm{~km} / \mathrm{h}$, which would significantly promote the economic and social development in the region. Inside Shanghai city, the extension of the existing line connects two airports as well as other public transport systems. Therefore, the efficiency of the integrated transport system would be improved due to seamless transfer. In addition, the high-speed maglev line could serve as an exemplary inter-city line for long-distance transport. The engineering experiences involved in these projects will be accumulated for further research and development.

However, the Shanghai-Hangzhou high-speed maglev project is very controversial. The debate around the project not only focuses on the comparison between the maglev and the traditional high-speed rail techniques, but also concerns the environmental impacts. The project has been suspended due to the debates and the resistances initiated by the residents of the area [15]. Particularly, after the opening of the Shanghai-Hangzhou high-speed railway line, the project has been shelved. Only some stops are reserved in the Hongqiao Airport station and Hangzhou East railway station.

For the proposed project, a systematic comparison between the maglev and the high-speed rail systems has not yet been carried out. Today, the research and construction of maglev lines are the subjects of more and more attention in China. Therefore, it is meaningful to explore a standardised approach for evaluating and ranking the project alternatives or competitive projects.

\subsection{The data basis of Shanghai-Hangzhou high-speed maglev project}

The evaluation is carried out based on the available data in [14]. According to the feasibility study, the construction of the project was expected to culminate in 2012. In the process of Standardised Evaluation, the value with the annuity method is taken from the data three years after the accomplishment of construction. At that time, in the German context, the capacity and traffic flow usually arrive at a stable level. However, the period of the increasing of performance in operations takes a relatively long time in China. Therefore, in this paper the data in 2022, which is the end of the middle term in [14], is taken as the benchmark for calculating annuity.

In [14], the forecast for traffic flow is carried out with the classical four-step model [16]. Inside the Shanghai city, 1,059 traffic zones are modelled, covering the whole area of the city of $6,340 \mathrm{~km}^{2}$. The maglev system is modelled as a part of the urban public transport system, with consideration given to its integration and the transfer with other means of public transport. A survey of passengers is conducted between Shanghai and Hangzhou. Furthermore, the utility function, the modal split, as well as the induced traffic volume are calculated. The result is used as one of the most important inputs for further evaluation.

The infrastructure planning and design are specified in detail in [14], which includes the layout of the line, the stations, the bridges and the track structure, the power supply system, the operation control system, the communication system, the maintenance plan, as well as the facilities of environmental protection and energy saving. The construction and maintenance costs of the infrastructure facilities will be used to determine the costs of infrastructure debt service and maintenance (see Section 5.2).

The train type TR08 is chosen, since it was at the time of design, the only train type that has passed the safety assessment and other required certifications in China. The operating program is designed with consideration of the integration between urban public transport and inter-city transport. Two depots are set at Hongqiao-Airport station and Hangzhou East station, with the Hongqiao-Airport station serving as the overhaul base for vehicle maintenance. In Section 5.1, the balance of operating and maintenance costs is calculated based on the information provided in [14].

\section{EVALUATION PROCESS AND RESULTS}

As described in Section 3, the evaluation process starts with calculating the balance of the sub-indicators for operations and maintenance with a comparison between the "with case" and the "without case". Then, the costs of infrastructure debt service and maintenance are determined for the "with case". Finally the result of the evaluation is derived. As the first implementation to assess the usability of the Standardised Evaluation, the investigation is only carried out on the evaluation indication E1.

\subsection{Calculating the balance of the sub-indicators}

The sub-indicators are evaluated at first through calculating the operating costs of public transport, the travel time in the form of costs, the car operating costs, the accident damages, and the costs for 
emissions. The "with case" and the "without case" are compared in a monetary form. The balance of an indicator will be calculated as the difference between the "with case" and the "without case". For example, if the costs of the "with case" are less than those of the "without case", the balance of the indicator will be set as a positive value, which represents the benefit resulted from the said project.

In the Standardised Evaluation, all calculations are based on a yearly time interval. By doing this, the annuity method (see Section 3.1) is used for the calculation of the infrastructure and vehicle (capital) costs. All other costs and benefits are determined as constant annual amounts taken either from the cost planning (e.g. public transportation operating costs) or from the transportation demand model (e.g. traffic capacity in motorized private transportation). At the same time, a constant annual traffic demand and a uniform price index are assumed. The price index is specified as a part of the Standardised Evaluation and serves to ensure that evaluations from different regions and different years can be fairly compared to one another. In addition to the price index, the requirements for conducting the Standardised Evaluation are also described. The price index and these requirements are updated every few years on behalf of the Federal States of Germany.

The operating costs of the maglev project include among others the costs of vehicle debt service, the maintenance costs, the energy costs, and the personnel costs, which are based on the data from the existing maglev line between Pudong-Airport and Longyang-Metro station and simulation results presented in [14]. The calculation of the debt service per vehicle is performed using the annuity method. According to [14], the service lives of the vehicles are taken as 35 years. The total investment cost of the vehicle is 7,139.19 million CNY. According to Equation 1 and taking the interest rate as 3\%, the annuity factor is 0.0510 , and the annuity of vehicle debt service is 345.89 million CNY.

In the Standardised Evaluation, the time-based and mileage-based maintenance costs for vehicles should be taken into consideration. In [14], the annual mileage-based maintenance costs (21.41 million CNY) for vehicles are available. Instead of the time-based maintenance costs, the annual material costs (20.70 million CNY) for vehicle maintenance are used in this paper. The annual maintenance costs for infrastructure are 515.81 million CNY, the calculation of which is described in Section 5.2.

Energy consumption in maglev systems is mainly centred on traction, levitation, as well as air-conditioning and lighting. According to simulation results, the annual expenditure due to energy consumption in 2022 would be 294.30 million CNY. The Standardised Evaluation system calculates personnel costs according to certain groups of employees, including drivers, station staff, safety staff, and train inspectors. The annual personnel costs for selected groups of employees in 2022 amount to 100.28 million CNY. As the sum of the costs of vehicle debt service, the maintenance costs, the energy costs, and the personnel costs, the total operating costs for the maglev project are $1,298.40$ million CNY. For the "without case", the predicted annual costs for railway systems is 618.63 million CNY. Therefore, the balance of public transport is presented as -679.77 million CNY, which is the difference between the operating costs of public transport in the "with case" and the "without case".

The reduced costs for travel time are calculated based on the forecast traffic flow and the travel time. In [14], the saved costs from travel time are calculated as:

$$
N=\left(\frac{Q}{v_{0}}-\frac{Q}{v_{1}}\right) \cdot G
$$

where:

$N$-reduced costs from saved travel time [CNY];

$Q$-passenger-kilometre in the year 2022 [pkm];

$v_{0}$-velocity of other means of transport for "without case" [km/h];

$v_{1}$-velocity of maglev systems for "with case" $[\mathrm{km} / \mathrm{h}]$;

$G$-cost factor for saved time [CNY/h].

According to the forecast Gross Domestic Product (GDP), the cost factor for saved time in 2022 is taken as $61.39 \mathrm{CNY} /$ Hour [14]. Therefore, the balance of the saved travel time is $3,081.79$ million CNY. If some or all of the trips of car users are transitioned from private traffic to maglev systems, the benefit is that those car users will have a reduction in their car operating costs. To determine these cost savings, the length (in $\mathrm{km}$ ) should be calculated for each saved trip and then separated into the categories of trips within city limits and trips outside of city limits. For both trip types, there are different cost rates per passenger-kilometre. These cost rates are calculated based on the average operating costs of typical vehicles. However, the required data for calculating the balance of car operating costs is not yet available. The reduced costs of accident damages are calculated in [14] as 85.96 milIion CNY. This value can be applied directly as the balance of accident damages. In the Standardised Evaluation, the $\mathrm{CO}_{2}$ and other polluting emissions, as well as the noise pollution should be evaluated. In [14], the benefits from the point of view of environmental improvement are evaluated as 168.17 million CNY. The value is applied as the total balance of the emissions.

In Table 1, the balance of the sub-indicators to compare the "with case" and the "without case" is listed. The sum of the monetary value in the amount of 2,656.15 million CNY can be conceived as the annual benefits of the implemented maglev project. 
Table 1 - Balance of the sub-indicators

\begin{tabular}{||l|c||}
\hline \multicolumn{1}{|c|}{ Sub-indicator } & $\begin{array}{c}\text { Monetary value } \\
\text { [million CNY/year] }\end{array}$ \\
\hline \hline $\begin{array}{l}\text { Balance of operating costs for } \\
\text { public transport }\end{array}$ & -679.77 \\
\hline Balance of saved travel time & $3,081.79$ \\
\hline $\begin{array}{l}\text { Balance of private transportation } \\
\text { operating costs }\end{array}$ & Not available \\
\hline Balance of accident damages & 85.96 \\
\hline Balance of emissions & 168.17 \\
\hline $\begin{array}{l}\text { Benefits (Sum of the monetary } \\
\text { value above) }\end{array}$ & $2,656.15$ \\
\hline
\end{tabular}

\subsection{Determination of the costs of infrastructure debt service and maintenance}

The costs of infrastructure debt service are derived through the annuity method. The costs are calculated for different types of infrastructure facilities. In [14], the investment costs and the service life for the facilities are provided. Taking the interest rate as 3\%, the annuity factors and the annuity can be calculated according to Equation 1.
For some investments, an explicit service life of the related infrastructure facilities is not available. These investments consist of the costs for the preparation of projects, the preparation for construction (e.g. changes of roads), special costs and the costs of greenbelt along the line. Since the service life of these investments can be regarded as infinite, the annuity factor is taken as 0.0300 , which is the interest rate applied for evaluation. The total investments in the facilities with infinite service life are 9,158.11 million CNY [14], and the annuity is 274.74 million CNY/year.

Table 2 shows the items for investments, the investment costs, the service life, the annuity factor, as well as the calculated annuity. The total annuity for infrastructure investments is 1,318.89 million CNY/year.

Furthermore, the maintenance costs can be calculated, respectively. This calculation is only carried out for the facilities with a given service life. The cost factor is based on the information provided in [14], with certain adjustment according to the Standardised Evaluation. The adjustment of the cost factors will be discussed in Section 6. Table 3 lists the cost factor and

Table 2 - Annuity for infrastructure facilities with a finite service life

\begin{tabular}{||l|c|c|c|c||}
\hline \multicolumn{1}{||}{ Items } & $\begin{array}{c}\text { Investment cost } \\
\text { [million CNY/year] }\end{array}$ & $\begin{array}{c}\text { Service life } \\
\text { [years] }\end{array}$ & $\begin{array}{c}\text { Annuity } \\
\text { factor [-] }\end{array}$ & $\begin{array}{c}\text { Annuity } \\
\text { [million CNY/year] }\end{array}$ \\
\hline \hline Stations & 221.08 & 40 & 0.0433 & 9.57 \\
\hline Tracks & $14,175.34$ & 80 & 0.0331 & 469.20 \\
\hline Roads for maintenance & 646.21 & 40 & 0.0433 & 27.98 \\
\hline Housing and other facilities & 943.15 & 60 & 0.0361 & 34.05 \\
\hline Power supply systems & 7579.02 & 40 & 0.0433 & 328.17 \\
\hline Operations control system & 2780.13 & 30 & 0.051 & 141.79 \\
\hline Communication system & 242.95 & 20 & 0.0672 & 16.33 \\
\hline Noise absorption & 49.80 & 25 & 0.0574 & 2.86 \\
\hline Equipment and furniture & 121.14 & 10 & 0.1172 & 14.20 \\
\hline Investments without service life & $9,158.11$ & - & 0.0300 & 274.74 \\
\hline Sum & $35,916.93$ & - & - & $1,318.89$ \\
\hline
\end{tabular}

Table 3 - Annuity of maintenance costs for infrastructure facilities

\begin{tabular}{||l|c|c|c||}
\hline \multicolumn{1}{|c|}{ Items } & Investment cost [million CNY/year] & Cost factor [\%] & Annuity [million CNY/year] \\
\hline \hline Stations & 221.08 & 1.0 & 221.08 \\
\hline Tracks & $14,175.34$ & 1.0 & $14,175.34$ \\
\hline Roads for maintenance & 646.21 & 1.0 & 646.21 \\
\hline Housing and other facilities & 943.15 & 2.0 & $1,886.30$ \\
\hline Power supply systems & $7,579.02$ & 2.5 & $18,947.56$ \\
\hline Operations control system & $2,780.13$ & 5.0 & $13,900.65$ \\
\hline Communication system & 242.95 & 5.0 & $1,214.76$ \\
\hline Noise absorption & 49.80 & 2.1 & 104.58 \\
\hline Equipment and furniture & 121.14 & 4.0 & 484.54 \\
\hline Sum & $26,758.82$ & - & 515.81 \\
\hline
\end{tabular}


the annuity. The calculated total annuity for infrastructure maintenance is used to evaluate the balance of operating costs for public transport (see Section 5.1).

\subsection{Results of evaluation}

With the evaluated value for the sub-indicators and the annuity costs for infrastructure investment, the final evaluation results are shown in Table 4.

Table 4 - Evaluation results of Shanghai-Hangzhou maglev project

\begin{tabular}{||l||c||}
\hline Annual benefits [million CNY/year] & $2,656.15$ \\
\hline $\begin{array}{l}\text { Annual infrastructure investment } \\
\text { [million CNY/year] }\end{array}$ & $1,318.89$ \\
\hline $\begin{array}{l}\text { Difference between benefits and costs } \\
\text { [million CNY/year] }\end{array}$ & $1,337.26$ \\
\hline $\begin{array}{l}\text { Benefit-cost indicator E1 (Quotient of } \\
\text { benefits and costs) }\end{array}$ & 2.01 \\
\hline
\end{tabular}

Through evaluating the planned Shanghai-Hangzhou project, the results show that the annuity of the overall economic benefits exceeds the annual infrastructure investment. The annual benefits are 2,656.15 million CNY/year, and the annual costs are $1,318.89$ million $\mathrm{CNY} /$ year. The overall benefit of the project amounts to more than twice its cost.

It should be noted, that the benefits of the project have been underestimated during the evaluation process. For example, since the data for car operating costs are not available, the benefits of savings in that regard are not included. Therefore, the benefits of the Shanghai-Hangzhou maglev project may prove to be more significant if all the required data are present.

\section{DISCUSSION AND CONCLUSION}

In this paper, the economic evaluation for Shanghai-Hangzhou maglev project is carried out according to the German Standardised Evaluation. One of the most important contributions of this work is to demonstrate the applicability of the Standardised Evaluation for a high-speed maglev project. With the Standardised Evaluation, the evidence of economic benefit can be presented in a transparent and systematic way. The result can be used to prove the project's profitability and to compare and rank different projects or project alternatives.

The benefit-cost indicator E1 with the value 2.01 can be perceived so that the project is worth being supported. It will be provided as a quantity-based evaluation result for the decision makers. However, the final decision also depends on the political context, which is not included in the Standardised Evaluation. One of the main reasons for the suspension of Shanghai-Hangzhou maglev project was due to the rapid development of the conventional high-speed rail in China after the year 2007. There are still people questioning whether the decision to implement high-speed rail projects should be made after comprehensive, transparent comparison and evaluation. The group that supports high-speed rail projects believes the technology of high-speed rail systems is relatively mature, and the people cannot afford long-term debates leading to the loss of the opportunity for development.

Nevertheless, the decision process related to the political framework is beyond the scope of this paper; the experiences of using the Standardised Evaluation in Germany still show the necessity of a formal, standardised process for evaluating different projects or project alternatives. The indicators included in the Standardised Evaluation will be evaluated for these projects through a unified approach. The controversial aspects, which cannot be evaluated objectively, can be at first excluded from the evaluation. The benefits and costs of the projects or project alternatives will be compared through a widely accepted and transparent procedure. Planners, decision makers and general public are able to assess the feasibility and profitability of different projects on a common basis. Meanwhile, the experiences of applying the method will also give feedbacks for further developments of the method. Therefore, the acceptance and the application of the method will be improved continuously.

The practices in Germany can also be compared and transferred to other countries, especially China, which has plenty of maglev projects to be implemented in the next years. In [14], the Shanghai-Hangzhou maglev project is evaluated based on the method regulated in [17]. Comparing the two approaches, a similar process is applied in collecting the static data (e.g. determination of the investment of infrastructure). However, there are the following main differences in the evaluation of indicators and the selection of parameters:

1) The final evaluation indicators: With the German Standardised Evaluation, the annuity method is applied to compare the benefits and costs. If the benefit-cost indicator $\mathrm{E} 1$ is higher than 1 , an investment project can be accepted. In [17], the criterion of acceptance is the internal rate of return being higher than the social discount rate. In principle, both of these approaches belong to dynamic evaluation. However, the benefit-cost indicator E1 is more suitable for comparing competitive projects.

2) The selected evaluation indicators: The savings in car operating costs are evaluated as the main contribution of benefits in the German Standardised Evaluation. The balance of savings in car operating costs has not been considered in [17] yet. The riding comfort is used in [17] directly to evaluate the benefit of a project. In Germany, it is used as a qualitative E2-indicator without being included in the cost-benefit analysis. 
3) The parameters for maintenance costs: The difference in the selected annuity factors of maintenance costs for the two approaches is considerable. For example, the annuity factor in [14] is $0.3 \%$, while the factor is set as $7 \%$ in the Standardised Evaluation [2]. In this work, an intermediate value of $5 \%$ is applied. The difference of annuity factors is caused by the different cost structure. In [17], the costs are calculated mainly for the expenditure on materials and equipment. In Germany, the costs of human power and software account for a large proportion.

4) The evaluation of environmental impacts: In China, there is no standardised method to evaluate the environmental impacts of a public transport project. In Germany, the evaluation procedure and its related parameters are specified in the Standardised Evaluation for different types of emissions. Critically, the procedure also considers the negative impacts caused by the investigated project. The indicators can be determined through the type and amount of energy consumption.

In recent years, the research and development of high-speed maglev systems has been gaining increasing interest. The lesson learnt in the Shanghai-Hangzhou maglev project indicates the necessity of establishing a systematic evaluation method in advance, in order to provide the public and decision makers with a comprehensive view. The work presented in this paper can be regarded as a starting point for the evaluation of high-speed maglev projects. The following developments are suggested in order to achieve an objective and transparent evaluation process:

A comprehensive costs structure with the calibrated parameters should be established in order to evaluate the indicators and future trends. Based on the predicted traffic flow and the scheduled operating program, the construction costs, the operating costs, and the maintenance costs will be calculated, taking the factor of time into consideration. For maglev projects in China particularly, the development of manpower costs and the calculation of time-based and mileage-based maintenance costs for vehicles should be fully investigated. A research project on the maintenance costs for vehicles over their entire life-cycle is now currently being carried out by the authors and a Chinese rolling stock manufacturer.

The environmental impact plays an important role in the evaluation process of maglev projects. The investigation should be based on the structure of energy consumption and the emission levels in different time periods. In [17], the evaluation method for emissions is specified. However, the evaluation process for the effects of $\mathrm{CO}_{2}$ emissions and the effects of electromagnetic radiation on human health are not included. It is necessary to standardise the evaluation of these aspects for high-speed maglev projects in China.
During the planning process, a standardised evaluation method can be integrated to achieve an optimised design. The final evaluation indicators should be applied in the objective function of the optimisation model. The effects of changing design parameters can be directly measured in terms of the evaluation indicators. For example, the final evaluation results and the maintenance costs can be traced back to the design of the maglev trains. The sensitivity analysis in the Standardised Evaluation will be seamlessly integrated within the optimisation model. Hence, a comprehensive designing, planning, simulation, evaluation and optimisation model will be established through applying a standardised evaluation on high-speed maglev projects.

崔勇; Stefan Tritschler; Ullrich Martin; 莫凡

\section{沪杭高速磁浮项目标准化评估}

近年来, 高速磁浮系统再次受到关注。即使取得了技 术上的成功, 目前仍然缺乏一种系统和透明的评估高速磁 浮项目的方法, 这妨碍了系统的进一步应用。在德国, 标 准化评估的方法已经成为决策获得公共财政支持的前提, 它必须应用于所有投资总额超过两千五百万欧元的城市公 共交通项目。本文将使用标准化评估方法对沪杭磁浮项目 进行评估。其中最重要的贡献是展示了标准化评估对于高 速磁浮项目的适用性。通过标准化评估, 宏观与微观经济 意义上的收益得以被系统与透明的展示, 其结果可以被用 于证明项目的盈利能力并可以对不同的项目与选项进行排 序。

标准化评估; 高速磁浮; 交通系统设计

\section{REFERENCES}

[1] Interplan Consult GmbH. Standardisierte Bewertung von Verkehrswegeinvestitionen im schienengebundenen öffentlichen Personennahverkehr - Version 2016. München: Bundesministers für Verkehr und digitale Infrastruktur; 2016.

[2] Interplan Consult GmbH, VWI Verkehrswissenschaftliches Institut Stuttgart GmbH. Standardisierte Bewertung von Verkehrswegeinvestitionen des ÖPNV und Folgekostenrechnung - Version 2006. Berlin, München, Stuttgart: Bundesministers für Verkehr, Bau und Stadtentwicklung; 2006.

[3] Lynch T. Maglev and high speed rail system environmental energy and economic benefit evaluation in Florida: a comparative analysis. SAE Transactions. 1990;99(5): 1016-1048.

[4] Liu R, Deng Y. Comparing operating characteristics of high-speed rail and maglev systems: case study of Beijing-Shanghai corridor. Transportation Research Record: Journal of the Transportation Research Board. 2004;1863: 19-27.

[5] Vuchic VR, Casello JM. An evaluation of maglev technology and its comparison with high speed rail. Transportation Quarterly. 2002;56(2): 33-50.

[6] Atzpodien HC. Transrapid Maglev system-fields of application. In: MAGLEV'2006: The 19 $19^{\text {th }}$ International 
Conference on Magnetically Levitated Systems and Linear Drives. 13-15 September 2006, Dresden, Germany.

[7] Kato H, Shibahara N, Osada M, Hayashi Y. A life cycle assessment for evaluating environmental impacts of inter-regional high-speed mass transit projects. Journal of the Eastern Asia Society for Transportation Studies. 2005;6: 3211-3224.

[8] Shanghai Academy of Environmental Sciences. [The Environment Impacts of Shanghai-Hangzhou Maglev Project]. Shanghai Municipal Government. 2006. Published 31 March 2016 at: http://www.envir.gov.cn

[9] Janic M. Multicriteria evaluation of high-speed rail, transrapid maglev and air passenger transport in Europe. Transportation Planning and Technology. 2003;26(6): 491-512.

[10] Naumann R, Schach R, Jehle P. An entire comparison of maglev and high-speed railway systems. In: MAGLEV'2006: The $19^{\text {th }}$ International Conference on Magnetically Levitated Systems and Linear Drives. 13-15 September 2006, Dresden, Germany.

[11] Macharis C, Bernardini A. Reviewing the use of Multi-Criteria Decision Analysis for the evaluation of transport projects: Time for a multi-actor approach. Transport Policy. 2015;37: 177-186.

[12] Martin U. Performance Evaluation. In: Hansen IA, Pachl J (eds.) Railway Timetabling \& Operations.
Analysis Modelling Optimisation Simulation Performance Evaluation. Germany: Eurailpress DW Media Group; 2014. p. 275-293.

[13] Heimel G. Nutzen-Kosten-Untersuchung zur S-BahnTrassenführung im Stadtgebiet Offenbach/Main: durchgeführt in Anlehnung an die Anleitung für die standardisierte Bewertung von Verkehrswegeinvestitionen des ÖPNV. Stadt Offenbach am Main, Dezernat VI, Germany;1983.

[14] Shanghai Maglev Engineering Technology Research Center, Shanghai Maglev Transportation Development Co., Ltd., The Third Railway Survey and Design Institute Group Co. [The report of feasibility study on Shanghai-Hangzhou maglev inter-city project]. Shanghai Municipal Government; 2006.

[15] Chen R, Taylor S. Hundreds protest Shanghai maglev rail extension. Reuters. January 12 2008. Available from: https://www.reuters.com/article/us-china-maglev-protest/hundreds-protest-shanghai-maglev-rail-extension-idUSPEK32757920080112 [Accessed 11th February 2018]

[16] Manheim ML. Fundamentals of Transportation Systems Analysis. Vol. 1. Cambridge, MA: MIT Press; 1979.

[17] National Development and Reform Commission of the People's Republic of China: [Economic Evaluation Methods and Parameters for Construction Project ( $3^{\text {rd }}$ Ed.)]. Beijing, China: China Planning Press; 2006. 